\title{
UPAYA PENINGKATAN KUALITAS HIDUP DENGAN PENERAPAN POLA HIDUP SEHAT PADA PENDERITA DIABETES MELLITUS DAN HIPERTENSI DALAM KLUB PROLANIS
}

\section{EFFORTS TO IMPROVE THE QUALITY OF LIFE WITH THE IMPLEMENTATION OF THE HEALTHY LIVING PATTERNS IN PEOPLE WITH DIABETES MELLITUS AND HYPERTENSION IN PROLANIS CLUB}

\author{
Azrimaidaliza $^{\left.1^{*}\right)}$, Isniati $^{1)}$, Rozaliny Asri $^{2)}$, Annisa $^{1)}$, Aisyah Mardina ${ }^{1)}$, Refni Sarita $^{1)}$ \\ ${ }^{1)}$ Fakultas Kesehatan Masyarakat, Universitas Andalas, \\ Email: azrimaidaliza@ph.unand.ac.id; yetisniati@gmail.com; annisa.giziunand@ gmail.com; \\ aisyahmardina1@gmail.com \\ ${ }^{2)}$ Yayasan Rumah Sakit Islam Ibnu Sina Padang, Email: asrirozaliny@ gmail.com
}

\begin{abstract}
ABSTRAK
Penyakit tidak menular seperti DM, jantung, tekanan darah tinggi, kanker, stress dan penyakit tidak menular lainnya disebabkan karena pola hidup tidak sehat. Upaya yang dapat dilakukan untuk meningkatkan kualitas hidup penderita DM dan hipertensi salah satunya adalah kegiatan Komunikasi Informasi dan Edukasi secara rutin untuk meningkatkan pengetahuan anggota klub Prolanis, yaitu suatu sistem pelayanan kesehatan dan pendekatan proaktif yang dilaksanakan secara integritas yang melibatkan peserta, fasilitas kesehatan tingkat pertama seperti Puskesmas, dan BPJS Kesehatan sehingga diharapkan anggota klub dapat menerapkan pola hidup sehat dalam kehidupan sehari-hari berikut dapat berdampak baik pada kondisi kesehatan mereka. Sasaran pengabdian adalah anggota klub prolanis di Puskesmas Lubuk Buaya dan Ambacang. Kegiatan pengabdian ini dilaksanakan berupa kegiatan Komunikasi Informasi dan Edukasi (KIE) dengan 4 (empat) tahapan yaitu kegiatan Pre-test, kegiatan Penyampaian materi tentang status gizi yang baik dan pola hidup sehat disertai dengan pemberian leafleat, kegiatan Post-test, dan pengukuran tekanan darah dan gula darah. Hasil kegiatan menunjukkan bahwa adanya peningkatan pengetahuan anggota klub tentang pola hidup sehat dengan melakukan kegiatan Pre-test dan Post-test. Tingkat pengetahuan anggota dengan kategori baik saat Pre-test adalah sebanyak 53,8\%, sedangkan pada saat Post-test meningkat menjadi 59,6\%. Kegiatan berjalan dengan lancar dan sasaran telah memahami konsep pola hidup sehat. Untuk kedepannya diharapkan kegiatan ini rutin dilaksanakan dan anggota prolanis yang ikut berpartisipasi jumlahnya lebih banyak dan lebih tenang sehingga pengabdi dapat memberikan kontribusi lebih dalam upaya untuk meningkatkan dan memperbaiki kebiasaan pola hidup pada anggota klub prolanis.
\end{abstract}

Kata Kunci : Prolanis, Tingkat Pengetahuan, Pola Hidup Sehat

\section{ABSTRACT}

The disease is not contagious like DM, heart, high blood pressure, cancer, stress and diseases are not contagious to other due to unhealthy life pattern. Efforts that can be done to improve the quality of life of sufferers of DM and hypertension one is information communication and education activities on a regular basis to improve the knowledge of members of the Club Prolanis, i.e., a system of health services and proactive approach undertaken in the integrity involving the participants, first-level health facilities such as Clinics, and Wellness BPJS so expect members of the Club can apply healthy living patterns in everyday life These can have an impact both on the condition of their health. The targets of the devotion is a member of the 
Club prolanis at the Clinics Down crocodiles and Ambacang. This devotion activities carried out in the form of Educational information and communication activities (IEC) with four (4) phases i.e. pre-release test activities, activities of the delivery of the material about the status of good nutrition and healthy living patterns accompanied by awarding leafleat, activity Posttest, and measurements of blood pressure and blood sugar. Results of activity indicates that an increase in knowledge Club members about the pattern of healthy living by performing activities of pre-and Post test-test. Level of knowledge of members by category whether Pretest is as much a 53.8\%, whereas at the time of the Post-test increased to 59.6\%. Activities running smoothly and target have understood the concept of healthy life patterns. For the future it is expected these activities regularly carried out and member of prolanis who participated in number more and more quiet so servants could contribute more in an effort to increase and improve habits the pattern of life on prolanis Club members.

Key words: Prolanis, Level Of Knowledge, The Pattern Of Healthy Living

\section{PENDAHULUAN}

Prolanis adalah suatu sistem pelayanan kesehatan dan pendekatan proaktif yang dilaksanakan secara integritas yang melibatkan peserta, fasilitas kesehatan tingkat pertama seperti Puskesmas, dan BPJS Kesehatan dalam rangka pemeliharaan kesehatan bagi peserta BPJS Kesehatan yang menderita penyakit kronis untuk mencapai kualitas hidup yang optimal dengan biaya pelayanan kesehatan yang efektif dan efisien. Sasaran dari kegiatan Prolanis adalah seluruh peserta BPJS Kesehatan penyandang penyakit kronis, khususnya Diabetes Melitus (DM) tipe 2 dan hipertensi.

Penyakit tidak menular (degeneratif) seperti DM, jantung, tekanan darah tinggi, kanker, stress dan penyakit tidak menular lainnya disebabkan karena pola hidup tidak sehat (Proverawati dan Rahmawati 2012). Pola hidup sehat adalah suatu gaya hidup dengan memperhatikan faktor-faktor tertentu yang mempengaruhi kesehatan, seperti makanan dan olah raga. Hal ini berkaitan dengan pola makan dan aktivitas fisik yang dilakukan seseorang (Sutanto, 2013).

Penyakit hipertensi berhubungan dengan DM dan gangguan metabolik lainnya atau yang disebut DM dengan komplikasi. Komplikasi terutama disebabkan oleh sistem arteri dan saraf yang dapat menyebabkan gangren dan penyakit kadiovaskular (penyakit jantung koroner dan stroke) (Hartono, 2014). Puskesmas berperan penting dalam menurunkan angka kejadian PTM terutama untuk penyakit DM dan hipertensi. Penyakit tersebut dirasa mampu ditangani di fasilitas kesehatan primer. Selain itu juga berperan penting dalam melakukan pencegahan terhadap komplikasi penyakit dengan melaksanakan skrining atau deteksi dini PTM.

Hasil Riset Kesehatan Dasar (Riskesdas) menunjukkan peningkatan prevalensi DM dari 1,1\% pada tahun 2007 meningkat menjadi 2,1\% pada tahun 2013. Hasil Riskesdas tahun 2013 melaporkan prevalensi Diabetes Mellitus yang terdiagnosis dokter di Sumatera Barat mencapai 1,3\% dan di Kota Padang mencapai $1,4 \%$. Sedangkan 
prevalensi nasional Hipertensi Pada

Penduduk Umur $>18$ Tahun adalah sebesar 29,8\% dan sedikit menurun pada tahun 2013 yaitu menjadi $25,8 \%$ dan di Provinsi Sumatera Barat adalah sebesar $31,2 \%$ pada tahun 2007 dan menurun pada tahun 2013 yaitu sebesar 22,6\% (berdasarkan pengukuran).

Berbagai penelitian sudah banyak membuktikan bahwa DM dan hipertensi dipengaruhi oleh gaya hidup yang tidak sehat. Penelitian yang dilakukan oleh Frankilawati (2013) menunjukkan bahwa ada hubungan $(\mathrm{p}<0.05)$ antara kejadian DM tipe II dengan pola makan yang buruk, responden memiliki 10 kali lipat risiko $(\mathrm{OR}=10,00)$ terhadap kejadian diabetes melitus tipe II.

\section{METODE}

Kegiatan pengabdian kepada masyarakat dilaksanakan berupa kegiatan Komunikasi Informasi dan Edukasi (KIE) dengan tahapan sebagai berikut;
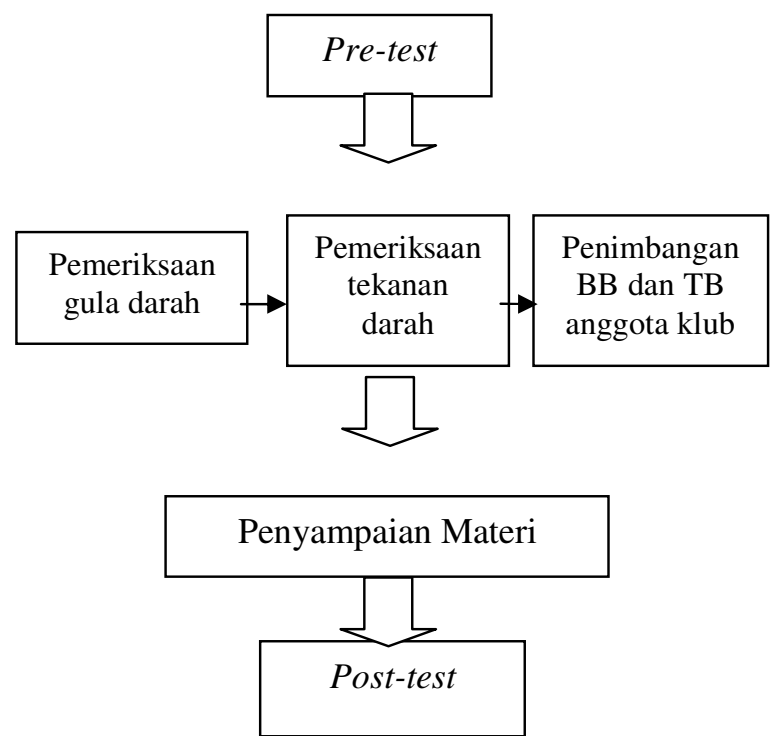

Gambar 1.Tahapan Kegiatan Pengabdian kepada Masyarakat
Kegiatan pengabdian kepada masyarakat akan dilaksanakan di Puskesmas Lubuk Buaya dan Puskesmas Ambacang. Pengabdian ini diharapkan sebahagian besar anggota prolanis memperoleh informasi mengenai pola hidup sehat yang kemudian diharapkan dapat menyampaikan kepada masyarakat maupun keluarga lainnya

Kegiatan pengabdian kepada masyarakat dilaksanakan dengan mempersiapkan materi penyuluhan, antara lain; (1) pengertian pola hidup sehat, (2) tips pola makan sehat dan gizi seimbang, (3) Pola makan diabetes dan hipertensi (4) pencegahan dan pengendalian diabetes dan hipertensi.

\section{HASIL DAN PEMBAHASAN}

Puskesmas Lubuk Buaya berlokasi di Jalan Adinegoro No.20 Lubuk Buaya Kecamatan Koto Tangah Kota Padang. Puskesmas ini merupakan salah satu Puskesmas rawatan yang terletak di pinggiran Kota Padang dengan luas wilayah kerja sekitar 59,34 $\mathrm{km}^{2}$ yang terdiri dari 6 kelurahan yaitu kelurahan Lubuk Buaya, Batang Kabung Ganting, Pasia Nan Tigo, Bungo Pasang, Parupuk Tabing, dan Dadok Tunggul Hitam. Beberapa pelayanan kesehatan yang terdapat di Puskesmas Lubuk Buaya adalah IGD 24 Jam, klinik bersalin, poli umum, poli gigi, poli KIA, Konsultasi gizi, klinik IMS, poli KB, poli lansia, laboratorium, dan akupresur. Salah satu layanan kesehatan yang diberikan adalah Prolanis, ditujukan agar penderita penyakit 
kronis dapat memelihara kesehatannya. Kegiatan klub Prolanis di Puskesmas ini dilaksanakan setiap hari Rabu pada minggu kedua setiap bulannya.

Puskesmas Ambacang merupakan Puskesmas non rawatan yang berlokasi di Jalan By Pass Pasar Ambacang Kecamatan Kuranji Kota Padang. Pelayanan kesehatan yang tersedia di Puskesmas Ambacang hampir sama dengan yang terdapat di Puskesmas Lubuk Buaya, hanya saja di Puskesmas ini tidak terdapat IGD 24 jam. Wilayah kerja Puskesmas Ambacang meliputi empat Kelurahan yaitu Kelurahan Pasar Ambacang, Anduring, Lubuk Lintah, dan Ampang yang luasnya sekitar $12 \mathrm{~km}^{2}$. Kegiatan klub Prolanis di Puskesmas Ambacang dilaksanakan setiap hari Rabu dan Sabtu pada minggu kedua setiap bulannya.

Keadaan bangunan kedua Puskesmas ini secara umum dalam kondisi yang baik terdiri dari 2 lantai dan memiliki halaman yang cukup besar sebagai fasilitas parkir dan kegiatan senam klub prolanis. Lokasi Puskesmas cukup strategis dan berada di pinggir jalan besar (umum), sehingga Puskesmas ini dapat dijangkau oleh masyarakat dengan menggunakan transportasi umum

Kegiatan pengabdian kepada masyarakat berupa "Upaya Peningkatan Kualitas Hidup dengan Penerapan Pola Hidup Sehat pada Penderita Diabetes Mellitus dan Hipertensi dalam Klub Prolanis Kota Padang Tahun 2018” dilaksanakan pada hari Rabu tanggal
11 Juli 2018 di Puskesmas Lubuk Buaya dan hari Sabtu tanggal 14 Juli 2018 yang berlokasi di Puskesmas Ambacang. Kegiatan yang dilakukan, sebagai berikut;

1. Persiapan sebelum kegiatan, meliputi;

a. Pengurusan izin untuk kegiatan pengabdian kepada masyarakat ke Dinas Kesehatan Kota Padang (surat keterangan kegiatan terlampir).

b. Pembuatan leafleat (terlampir).

c. Penyusunan kuesioner pre-test dan post-test untuk mengetahui tingkat pengetahuan anggota tentang buah dan sayur (kuesioner terlampir).

d. Pembuatan spanduk untuk kegiatan (terlampir).

e. Koordinasi dengan tenaga kesehatan khusunya pemegang program klub Prolanis di Puskesmas Lubuk Buaya dan Puskesmas Ambacang untuk mengizinkan anggota klub Prolanis mengikuti kegiatan.

f. Pembuatan materi/power point untuk kegiatan promosi konsumsi buah dan sayur (terlampir).

2. Pelaksanaan kegiatan "Upaya Peningkatan Kualitas Hidup dengan Penerapan Pola Hidup Sehat pada Penderita Diabetes Mellitus dan Hipertensi dalam Klub Prolanis Kota Padang Tahun 2018" sebagai berikut;

a. Kegiatan diikuti oleh; 52 orang yang terdiri dari 28 orang di Puskesmas Lubuk Buaya dan 28 orang di Puskesmas Ambacang. 
b. Kegiatan diawali dengan penjelasan kepada anggota klub Prolanis mengenai kegiatan pengabdian masyarakat yang akan dilakukan. Hal ini disampaikan oleh pemateri/penyuluh dibantu oleh petugas pemegang program Prolanis

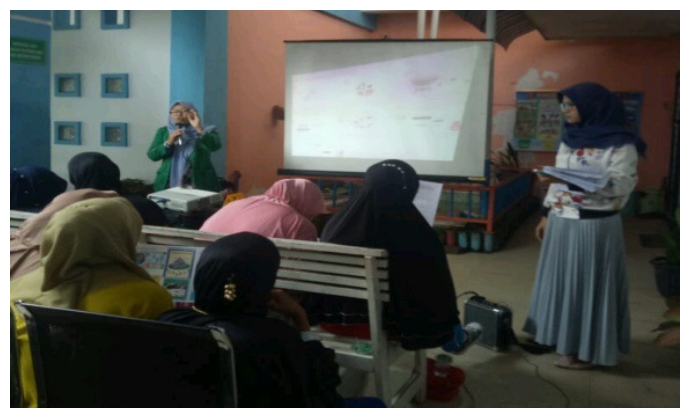

Gambar 2. Penjelasan kegiatan Pengabdian

kepada Masyarakat yang akan dilakukan

c. Kegiatan Kegiatan pre-test dilakukan sebelum disampaikannya materi tentang "Upaya Peningkatan Kualitas Hidup dengan Penerapan Pola Hidup Sehat pada Penderita Diabetes Mellitus dan Hipertensi dalam Klub Prolanis Kota Padang Tahun 2018”. Anggota klub diminta untuk menjawab beberapa pertanyaan (kuesioner) yang terkait dengan materi yang akan disampaikan.

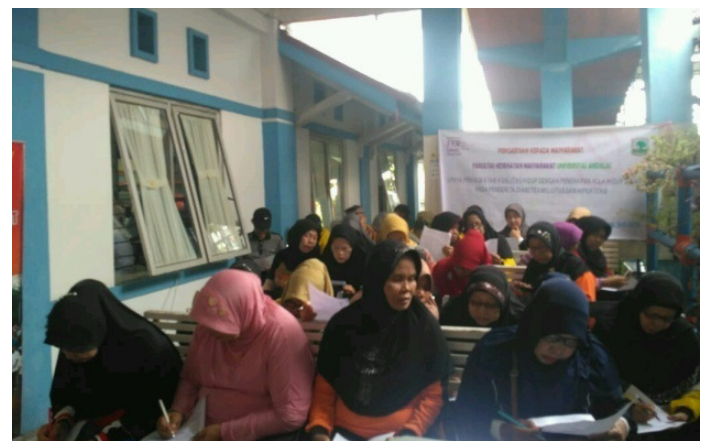

Gambar 3. Kegiatan Pre-test sebelum penyampaian materi penyuluhan d. Penyampaian materi oleh Penyuluh/pemateri dengan menggunakan metoda ceramah menggunakan media leaflet. Leaflet dibagikan kepada anggota klub pada saat penyuluhan dan leaflet dikumpulkan kembali pada saat kegiatan post-test. Setelah penyampaian materi, anggota diberi kesempatan untuk mengajukan pertanyaan. Anggota klub yang hadir dalam kegiatan ini cukup antusias dan semangat dengan materi yang disampaikan. Hal ini terlihat dari pertanyaan-pertanyaan yang diajukan. Hanya saja, ada beberapa orang yang membuat keributan sehingga sedikit mengganggu proses kegiatan yang berlangsung.

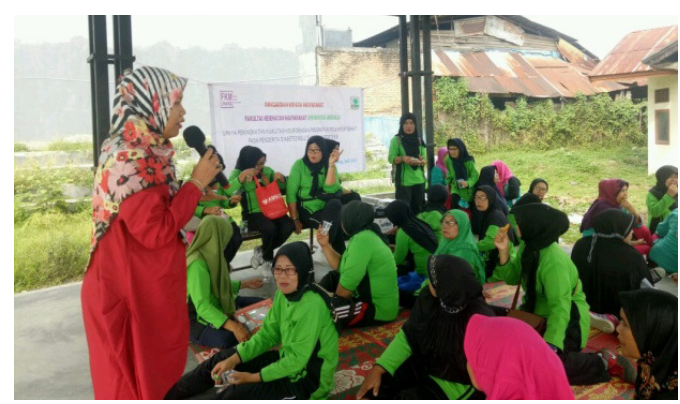

Gambar 4. Penyampaian materi oleh pengabdi

Gambaran karakteristik anggota, yaitu jenis kelamin anggota yang ikut kegiatan pengabdian dapat dilihat pada tabel 1 berikut; 
Tabel 1. Distribusi Frekuensi Karakteristik Anggota Menurut Jenis Kelamin

\begin{tabular}{lll}
\hline \multirow{2}{*}{ Jenis Kelamin } & \multicolumn{2}{l}{ Jumlah } \\
\cline { 2 - 3 } & $\mathrm{f}$ & $\%$ \\
\hline Laki-laki & 6 & 11.5 \\
Perempuan & 46 & 88.5 \\
Jumlah & 52 & 100,0 \\
\hline
\end{tabular}

Berdasarkan Tabel 1. dapat diketahui bahwa jenis kelamin anggota yang paling banyak adalah Perempuan yaitu sebanyak 46 orang $(85.5 \%)$.

f. Kegiatan post-test dilakukan setelah semua pertanyaan dari anggota selesai dijawab. Pada kegiatan post-test anggota diminta kembali untuk menjawab pertanyaan-pertanyaan dalam kuesioner mengenai pola hidup sehat. Pertanyaan yang terdapat pada kuesioner post-test tersebut sama dengan pertanyaan yang disampaikan pada kegiatan pre-test.

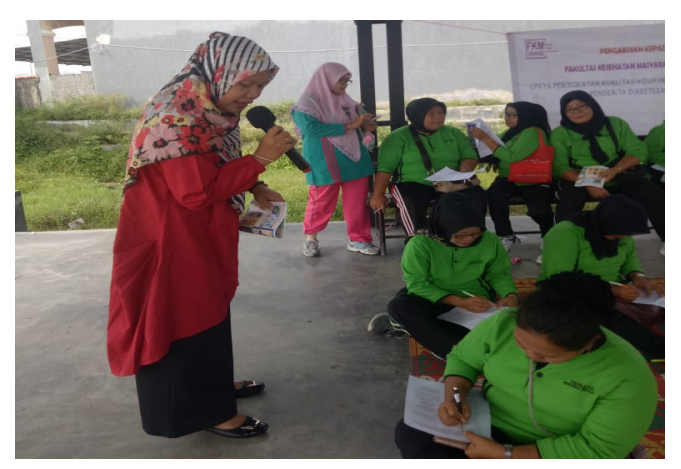

Gambar 5. Kegiatan Post-test setelah penyampaian materi penyuluhan

Tingkat pengetahuan gizi anggota klub yang ikut dalam kegiatan pengabdian dapat diketahui melalui pertanyaan yang diajukan, yaitu sebanyak 10 pertanyaan mengenai pola hidup sehat. Pengetahuan gizi anggota klub dikelompokkan menjadi 2 kategori, yaitu pengetahuan gizi baik dan pengetahuan gizi kurang. Pengetahuan gizi baik apabila anak dapat menjawab pertanyaan betul sebanyak $\geq$ 7 pertanyaan dan pengetahuan gizi kurang apabila ibu dapat menjawab pertanyaan betul sebanyak $<7$ pertanyaan.

Hasil kegiatan pre-test dan post-test menunjukkan gambaran tingkat pengetahuan gizi anak, dengan hasil sebagai berikut;

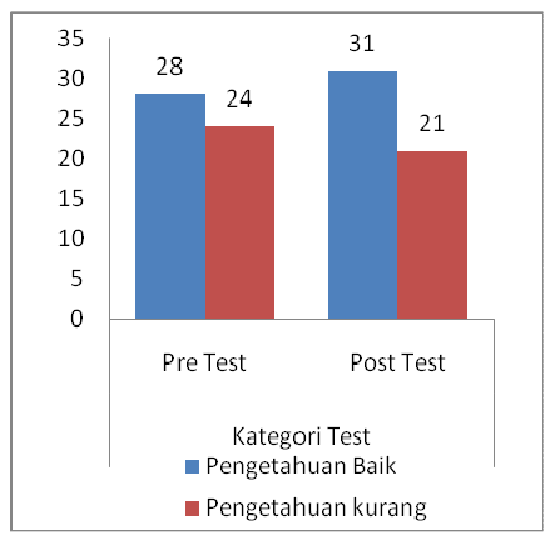

Grafik 1. Tingkat Pengetahuan Gizi Anak SD berdasarkan kegiatan Pre-test dan Post-test pada Kegiatan Pengabdian Kepada Masyarakat

Berdasarkan grafik di atas dapat diketahui bahwa terdapat peningkatan pengetahuan gizi anggota klub dengan melakukan kegiatan Pre-test dan Post-test. Tingkat pengetahuan anggota klub dengan kategori baik saat Pretest adalah sebanyak 28 orang (53.8\%), sedangkan pada saat Post-test meningkat menjadi 31 orang $(59.6 \%)$ yang memiliki tingkat pengetahuan baik.

Pengetahuan gizi anggota klub yang baik dapat meningkatkan penerapan pola hidup sehat yang baik juga pada penderita Diabetes Mellitus dan Hipertensi ini. Anggota klub 
diharapkan dapat meningkatkan pola hidup sehat sehingga kualitas hidup mereka menjadi lebih baik dan akan meningkat di masa-masa penyakit tersebut. Berbagai teori dan penelitian sudah membuktikan bahwa pengetahuan yang kurang baik adalah salah satu faktor yang dapat menimbulkan permasalahan gizi dan kesehatan.

g. Kegiatan pengabdian kepada anggota klub ditutup dengan kegiatan pengukuran $\mathrm{BB}, \mathrm{TB}$, Tekanan darah (TD), dan Gula Darah Sewaktu (GDS) yang dilakukan langsung di Puskesmas Gambaran status gizi anggota klub yang mengikuti kegiatan pengabdian kepada masyarakat dapat dilihat pada tabel berikut;

Tabel 2. Distribusi Frekuensi Status Gizi

\begin{tabular}{lll}
\multicolumn{3}{c}{ Anggota Klub Prolanis } \\
\hline \multirow{2}{*}{ Jumlah anak } & \multicolumn{2}{l}{ Jumlah } \\
\cline { 2 - 3 } & $\mathrm{f}$ & $\%$ \\
\hline Kurus & 2 & 3.8 \\
Normal & 22 & 42.4 \\
Gemuk & 28 & 53.8 \\
Jumlah & 52 & 100,0 \\
\hline
\end{tabular}

Berdasarkan Tabel 2. dapat diketahui bahwa lebih dari separuh anggota klub memiliki status gizi gemuk yaitu sebanyak 28 orang $(53.8 \%)$, namun juga terdapat anggota klub yang memiliki status gizi kurus, yaitu sebanyak 2 orang (3.8\%). Berdasarkan pengukuran tekanan darah diperoleh sebanyak 28 orang memiliki tekanan darah tinggi dan 16 orang normal. Berdasarkan pengukuran gula darah diperoleh sebanyak
14 orang memiliki gula darah tinggi dan 12 orang normal, dan sisanya tidak melakukan pengukuran.

Kegiatan pengabdian kepada masyarakat seperti yang dilakukan oleh pengabdi melalui kerjasama antar institusi kesehatan, salah satunya dengan Dinas Kesehatan Kota Padang dan Puskesmas merupakan salah satu upaya yang dapat dilakukan untuk meningkatkan pengetahuan masyarakat, khususnya mengenai pengetahuan gizi terkait pola hidup sehat pada anggota klub Prolanis. Pemahaman tentang pola hidup sehat melalui kegiatan promosi gizi diharapkan lebih efektif dan lestari sehingga meningkatkan Pengetahuan, Sikap dan Perilaku (PSP) tentang pola hidup sehat yang selanjutnya akan meningkatkan status kesehatan anggota klub Prolanis.

Kegiatan pengabdian ini berupa promosi gizi terkait pola hidup sehat bagi penderita Diabetes Mellitus dan Hipertensi sesuai dengan yang direncanakan sebanyak 1 kali di 2 lokasi dengan tujuan agar dapat mencakup sasaran yang lebih luas dan lebih banyak. Kegiatan ini diharapkan tidak hanya terfokus pada anggota klub Prolanis saja yang diberi penyuluhan tetapi juga hendaknya anggota klub tersebut dapat menyampaikan ke temanteman di luar klub bahkan dapat menerapkannya dalam kehidupan sehari-hari atau di dalam rumah (menyampaikan kepada keluarga).

Beberapa keterbatasan yang ditemukan dalam kegiatan pengabdian antara lain; 
mencari waktu yang tepat dalam mengadakan kegiatan karena kegiatan ini diselipkan pada kegiatan klub Prolanis di Puskesmas. Kemudian di satu sisi mengumpulkan sejumlah anggota klub agar bisa tenang dan serius dalam mengikuti kegiatan merupakan tantangan tersendiri bagi pengabdi dan anggota mengingat jumlah anggota klub cukup banyak dan tidak semua yang bersedia mengikuti kegiatan sampai selesei.

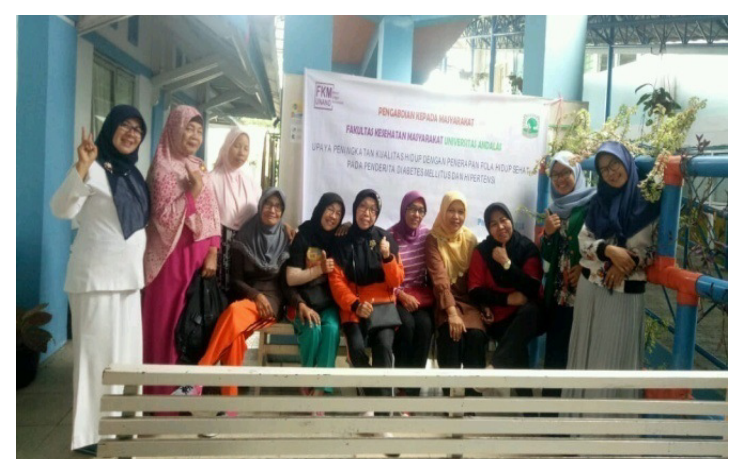

Gambar 6.Pengabdi bersama anggota klub dan petugas kesehatan Puskesmas

Secara umum kegiatan pengabdian kepada anggota klub Prolanis berjalan dengan lancar dan dapat mencapai tujuan ataupun target dari pengabdi, walaupun ada beberapa anggota klub yang membuat keributan sehingga mengganggu anggota klub lain yang sedang serius mengikuti kegiatan. Hal ini terlihat dari adanya peningkatan persentase pengetahuan anggota klub setelah diberikannya penyuluhan. Hasil yang lebih baik tentunya bisa diperoleh apabila penyuluhan dilakukan secara kontinyu.

Kedepannya, kegiatan pengabdian ini dapat dilakukan secara rutin dan tidak hanya dilakukan pada dua Puskesmas saja, tetapi dapat dilakukan di Puskesmas lainnya. Anggota klub yang terlibat dalam kegiatan ini diharapkan jumlahnya lebih banyak dengan metoda yang lebih baik dan suasana yang lebih mendukung, lebih tenang selama kegiatan berlangsung sehingga pengabdi dapat memberikan kontribusi yang lebih baik dalam upaya peningkatan kualitas hidup bagi penderita Diabetes Mellitus dan Hipertensi.

\section{KESIMPULAN}

a. Kegiatan pengabdian kepada masyarakat yang dilaksanakan di Puskesmas Lubuk Buaya dan Puskesmas Ambacang secara umum berjalan dengan lancar sesuai dengan yang direncanakan.

b. Kegiatan ini terdiri dari beberapa tahapan yaitu Pre-Test, Penyuluhan atau penyampaian materi terkait konsumsi buah dan sayur, Post-test, dan pengukuran BB, TB, TD dan Glukosa darah.

c. Anggota Klub Prolanis antusias dengan kegiatan yang dilaksanakan dibuktikan dengan kehadiran anggota klub dan keseriusannya dalam mendengarkan materi yang disampaikan. Anggota klub juga memberikan beberapa pertanyaan terkait materi yang disampaikan dan keluhan yang dialami saat melaksanakan pola hidup sehat.

d. Hasil kegiatan yang sudah dilakukan menggambarkan bahwa adanya peningkatan pengetahuan dan informasi anggota klub tentang pola hidup sehat, yang diharapkan anggota memiliki pola 
hidup sehat yang baik, selanjutnya memberikan dampak yang baik bagi kesehatan mereka pada usia lanjut.

\section{REFERENSI}

[1] BPJS Kesehatan. 2014. Buku Panduan Praktis Prolanis. terdapat pada http.//bpjskesehatan. go.id./bpjs/index.php.unduh/index/39 diakses pada 20 Februari 2018.

[2] Depkes RI. 2007. Riset Kesehatan Dasar Tahun 2007. Jakarta: Badan Penelitian dan Pengembangan Kesehatan Depkes RI.

[3] Depkes RI. 2013. Riset Kesehatan Dasar Tahun 2013. Jakarta: Badan Penelitian dan Pengembangan Kesehatan Depkes RI.

[4] Frankilawati DAM. 2013. Hubungan Antara Pola Makan, Genetik dan Kebiasaan Olahraga Terhadap Kejadian Diabetes Melitus Tipe II Di Wilayah
Kerja Puskesmas Nusukan, Surakarta. Surakarta: Universitas Muhammadiyah Surakarta.

[5] Hartono A, Rachmat M, Agustin CA, Rezkina E. 2014. Buku Ajar Ilmu Gizi. Jakarta: EGC.

[6] Kemenkes RI. 2014. Pusat Data dan Informasi Kemenkes RI: Situasi dan Analisis Diabetes. Jakarta: Kemenkes RI.

[7] Sutanto T. 2013. Diabetes Deteksi, Pencegahan, Pengobatan. Jakarta: PT Gramedia Pustaka Utama.

[8] Ramadhanisa A, Larasati T, Mayasari D. 2013. Hubungan Aktivitas Fisik dengan Kadar HbAlc Pasien Diabetes Melitus Tipe 2 Di Laboratorium Patologi Klinik RSUD dr. H. Abdul Moeloek Bandar Lampung. Kedokteran: Universitas Lampung.

[9] Proverawati, Atikah dan Rahmawati, Eni. 2012. Perilaku Hidup Bersih dan Sehat (PHBS). Yogyakarta: Nuha Medika. 